\title{
RESEARCH PAPER \\ Properties of Eco-Brick manufactured using Kenaf Fibre as matrix
}

\author{
Hanisom Abdullah ${ }^{1,}{ }^{*}$, Ahmad Kamil Jamaai ${ }^{2}$ \\ ${ }^{1,2}$ Universiti Pendidikan Sultan Idris, Tanjung Malim, Malaysia
}

\author{
Index Terms \\ Eco-Brick \\ Kenaf \\ Carbon Dioxide Mitigation
}

Received: 15 April 2015

Accepted: 23 November 2015

Published: 22 February 2015

\begin{abstract}
Eco-brick is an important environment-friendly strategy to mitigate carbon dioxide emission in building construction. For energy and resource efficient of eco-brick manufacturing, natural fibre and biomass waste can be utilised as matrix. The present study aims to evaluate the properties of concrete eco-brick manufactured using kenaf fibre matrix. The brick was produced by mixing kenaf fibre (MR grade), Portland cement and sand. The physical and mechanical properties of the eco-brick were evaluated according to the ASTM C73 method. The water absorption values of the eco-brick were in the range of 9.0-12.5 \%. Eco-brick produced from $0.5,1.0,1.5 \%$ and $2.0 \%$ kenaf fibre have flexure resistance to compression of 4693.9, 4335.6, 3879.3 and 3294.5 psi respectively. According to the ASTM C73 guidelines, the properties of eco-brick from mixture of 0.5$1.5 \%$ kenaf fibre produced in this study meet building material criteria for construction in moderate weather conditions.
\end{abstract}

(C) 2016 The Author(s). Published by TAF Publishing.

\section{INTRODUCTION}

In the construction industry, brick is considered as one of the most important materials especially for building walls. Conventionally, consumers' perception appreciates clay bricks over concrete bricks due to its higher mechanical strength and aesthetic value. In recent years however, there are concerns over the production of building materials that contribute to the greenhouse effect. Clay bricks making process requires firing of dried extruded mixture of clay, coal and water in kiln at temperature between $700-1100^{\circ} \mathrm{C}$. The whole process is energy intensive and generates large amount of carbon dioxide [1]. In fact, bricks have been identified as major $\mathrm{CO}_{2}$ low

\footnotetext{
*Corresponding author: Hanisom Abdullah

E-mail: hanisom@fsmt.upsi.edu.my
}

cost housing in Malaysia [2]. During the last five years, demand for concrete brick has emission contributor in the manufacturing of single storey been steadily increasing in the market. The improved standards and specification of concrete brick by architectural and technological facilities contributed to the increase production of concrete bricks [3]. Unlike clay bricks, concrete bricks are simpler to manufacture. The curing of concrete bricks does not require heating at high temperature therefore concrete bricks production is energy saving and emits minimal pollution [4]. With the increasing demand for sustainable eco- building material, it is important to incorporate environment- friendly elements into concrete bricks. Building materials can be assessed as suitable for the environment if it contains the following characteristics: $i$. base material is made with safe, recyclable or has agricultural waste content; ii. materials are sourced 
through preservation of the environment; iii. products that do not release toxic wastes; iv. materials that can save energy or water; and $\mathrm{v}$. products that contribute to a healthy and safe environment [5]. Fibre Reinforcing Concrete (FRC) is concrete containing fibrous material to increase the concrete's structural integrity. It contains short uniform discrete fibres arranged randomly. Basically there are two classifications of fibres in FRC production i.e synthetic fibres and natural fibres. The character of concrete reinforcing fibres change with various concrete, fibre materials, geometries, distribution, orientation, and density [6].

In recent decades, a number of studies have been conducted in connection with the mixture of lignocellulosic biomass fibres such as hemp, bamboo, sisal, jute, straw and animal fur in eco-bricks [7], [8], [9]. The main motive was to produce bricks reinforced with a composite mixture to obtain a more sustainable, non-toxic, using natural ingredients that may enhance mechanical strength of bricks. These types of bricks can be made without the combustion process, which contribute to low energy cost and reduce carbon dioxide emissions since biomass as a carbon neutralizer permanently lock up in the construction materials [4]. In addition, it is believed that natural fibres and grains close porous structure thus enhance the thermal insulation properties of existing brick products [7].

The present study aims to produce eco-concrete brick using kenaf fibres matrix and to assess its properties. Kenaf tree produced two types of fibre parts i.e bast and core. The bast fibre has high mechanical strength preferable in the manufacturing of polymer composites as an alternative to fibreglass. In Malaysian context, the National Kenaf and Tobacco Board are extensively promoting new innovations in the application of kenaf fibre for biomaterials production.

The evaluation of kenaf-reinforcing concrete brick is scarce in the literature. Therefore, the current study is significantly important to obtain fundamental understanding about the properties of reinforced ecobrick manufactured using kenaf fibre as matrix. This article reports preliminary results on the performance of eco-brick produced from various proportions of kenaf fibre, cement and sand. The properties evaluated in this study including water absorption rate and flexural strength. The results were compared with those of commercial engineering concrete brick according to the ASTM C73 standard specifications for calcium silicate brick [11].

\section{MATERIALS AND METHOD}

Materials. In this study, the materials used to prepare the eco-brick are kenaf fibre, Ordinary Portland Cement, sand and water. Kenaf fibre (MR grade) was obtained from the National Kenaf and Tobacco Board. The kenaf fibre was cut into particle size of $1 \mathrm{~cm}$. Ordinary Portland Cement (OPC) was used as binder. The commercially available OPC are mixtures of calcium oxide, silicon dioxide and aluminium oxide. The sand was dried and sieved to obtained particle size of $1 \mathrm{~mm} 2$. Production of eco-brick. The eco-bricks are composed of mixture of sand, OPC, water and kenaf fibre. A fixed ratio of sand, OPC and water (4:1:1, by weight) was used as binding agent to prepare the bricks. An amount of kenaf fibre (MR grade) varying from $0.5-2.0 \% \mathrm{w} / \mathrm{w}$ was then added to form matrix with the binder. The mixtures were pressed in mould (dimension $21 \times 9 \times 6 \mathrm{~cm} 3$ ) and left to cure at room temperature for 7 days. A control brick specimen (plain brick) was produced by mixing a similar proportion of OPC, sand and water without the addition of kenaf fibre.

Physical and mechanical properties of eco-brick. The microstructures of eco-bricks produced in this study were examined under the Scanning Electron Microscope (HITACHI SU8020UHR). For water absorption test, the ASTM C73 standard test method also procedures described previously in [10] were followed. There are two ways to conduct the water absorption test. The first method is by fully immersing the bricks in boiling water for $5 \mathrm{hrs}$ and then dried at room temperature for $19 \mathrm{hrs}$. Alternatively, the bricks could also be immersed in water at room temperature for $24 \mathrm{hrs}$. The amount of water absorbed was calculated using Eq. (1):

$\mathrm{PA}=(\mathrm{B} 1-\mathrm{B} 2) / \mathrm{B} 1 \mathrm{X} 100 \%$

$\mathrm{PA}=$ rate of water absorbed

B1 = weight of bricks before test $(\mathrm{kg})$

B2 = weight of bricks before test $(\mathrm{kg})$

To assess the bricks ability to resist deformation under load, a three-point flexural strength test (Model Instron) following ASTM C73 standard was applied. The Modulus of Rupture (MOR) of the bricks was calculated using Eq. (2). The MOR value obtained was then converted to compressive strength values (psi).

$\operatorname{MOR}(\mathrm{kg} / \mathrm{cm} 2)=3 \mathrm{PL} / 2 \mathrm{bh} 2$

MOR = Modulus of Rupture

$\mathrm{P}=$ load at fracture point $(\mathrm{kg})$

$\mathrm{L}=$ length of the support span $(\mathrm{cm})$

$\mathrm{b}=$ brick width $(\mathrm{cm})$ 
$\mathrm{d}=$ brick thickness $(\mathrm{cm})$

The procedures of physical and mechanical assessment described above were also conducted on control specimens. In this study, two control specimens were used i.e plain concrete brick (produced in this study) and a commercial engineering concrete brick (Fig. 1 a-b). All tests in this study were conducted in duplicates to improve data reliability.

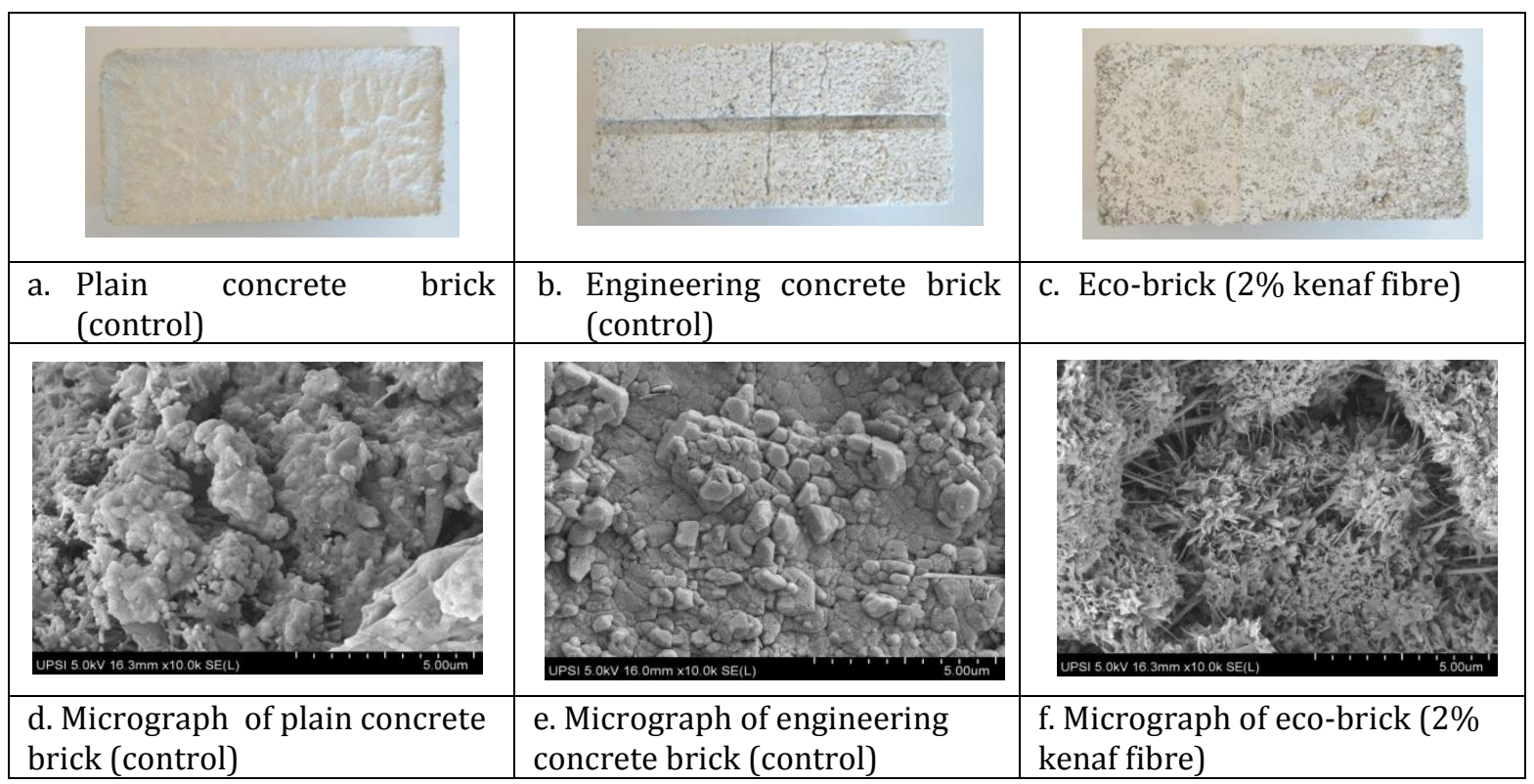

Fig. 1. Macro and microstructures of brick specimens.

\section{RESULTS}

Fig. 1(a-d) shows the nature of eco-brick (contains 2\% kenaf fibre) and control brick specimens and their micrographs respectively. The result indicated that the addition of kenaf fibre affected the microstructures composition of eco-brick. In Fig. 1 (f), the sand-cement aggregates were not clearly visible in the eco-brick surface microstructures, as opposed to the exposed aggregates in the control bricks (Fig. 1 (d-e). The kenaf fibre seems to form networking matrix with the binding agents created voids and pores in between. The intermingling of kenaf fibre with the binders is believed to influence the eco-brick water absorption rate and its mechanical strength. Fig. 2 illustrates water absorption rate of eco-bricks produced in this study. The results were benchmarked against those of controls and ASTM C73 standard for calcium silicate bricks application in moderate and severe weather conditions.

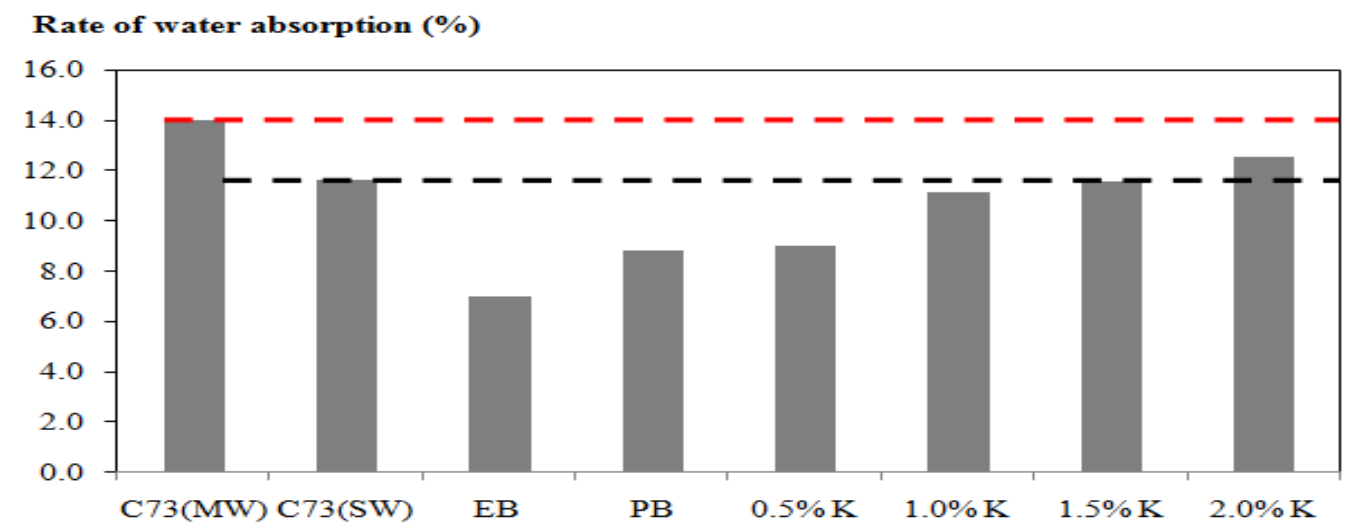

Fig. 2. Rate of water absorption of brick specimens. 
(Legend: C73 (MW); ASTM C73 guidelines for moderate weather application, C73 (SW); ASTM C73 guidelines for severe weather application, EB; engineering concrete brick, PB; control plain concrete brick, $0.5 \% \mathrm{~K}$; eco-brick contains $0.5 \%$ kenaf fibre, $1.0 \% \mathrm{~K}$; eco-brick contains $1.0 \%$ kenaf fibre, $1.5 \% \mathrm{~K}$; eco-brick contains $1.5 \%$ kenaf fibre, $2.0 \% \mathrm{~K}$; eco-brick contains $2.0 \%$ kenaf fibre). From Fig. 2, clearly the addition of kenaf fibre increased the water absorption rate in all the eco-bricks produced in this study as compared to the control bricks. The increased of water absorption is positively correlated with the amount of kenaf fibre added into the matrix. Kenaf fibre has good absorption capacity and geotextile material made from kenaf has been proven to effectively treated oil spillage in laboratory study [12]. The visible increased of pores developed between networking of kenaf fibre and binders as observed in Figure 1(f) may contribute to the increased of water absorption capacity of the eco-bricks. The porous structure of eco-brick could create a lot of micro channels and capillary force so as to retain more water than ordinary bricks. However, it is important to highlight that the water absorption rates of all eco-bricks produced in this study are well under the ASTM C73 specifications for moderate weather application. The eco-bricks contain $0.5-1.5 \%$ kenaf fibre also passed the ASTM C73 guidelines for severe weather conditions. These results would implicate potential application of eco-bricks to mitigate carbon emission for building construction in Malaysia. With the exception of brick contains $2.0 \%$ kenaf, other eco-bricks produced in this study also can be commercialized for application in the overseas under a more severe weather conditions. The ability of the eco-bricks to withstand deformation against load was assessed using a three- point flexural test and the compressive strength values are shown in Table 1. The results obtained in this study were compared to those of ASTM C73 standard specifications. From Table 1 , the compressive strength of eco-bricks produced from $0.5-1.5 \%$ kenaf fibre was found to be suitable for application in moderate weather conditions according to the ASTM C73 standard that requires a brick to have compressive strength value of 3500 psi and above.

TABLE 1

COMPRESSIVE STRENGTH VALUES OF BRICK SPECIMENS

\begin{tabular}{cc}
\hline \hline Specimen & Compressive strength (psi) \\
\hline C73 (MW) & 3500 \\
C73 (SW) & 5500 \\
EB & 5916 \\
PB & 5001 \\
$0.5 \% \mathrm{~K}$ & 4694 \\
$1.0 \% \mathrm{~K}$ & 4336 \\
$1.5 \% \mathrm{~K}$ & 3879 \\
$2.0 \% \mathrm{~K}$ & 3295 \\
\hline \hline
\end{tabular}

(Legend: C73 (MW); ASTM C73 guidelines for moderate weather application, C73 (SW); ASTM C73 guidelines for severe weather application, EB; engineering concrete brick, PB; control plain concrete brick, $0.5 \% \mathrm{~K}$; eco-brick contains $0.5 \%$ kenaf fibre, $1.0 \% \mathrm{~K}$; eco-brick contains $1.0 \%$ kenaf fibre, $1.5 \% \mathrm{~K}$; eco-brick contains $1.5 \%$ kenaf fibre, $2.0 \% \mathrm{~K}$; eco-brick contains $2.0 \%$ kenaf fibre). The compressive strength of eco-bricks produced in this study show a decreasing trend with the increase of kenaf fibre amount. It is speculated that the bonding of aggregateskenaf fibre in eco-brick is somehow weaker than the bonding of aggregates-aggregates in the control bricks. The networking formation observed in eco-bricks microstructure discussed in previous subsection also believed to aid in the spreading of force from the ecobricks surface when weighs were loaded. The compressive strength values of brick specimens (eco-brick and plain concrete bricks) produced in this study do not meet criteria of the ASTM C73 specifications for severe weather conditions ( $5500 \mathrm{psi}$ and above). This data gives further insights on the technical improvement needed to upgrade the mechanical strength of the eco-bricks products to meet all the ASTM C73 specifications especially in the aspect of fibre length parameter and weaving technique.

\section{CONCLUSION}

In this study, several conclusions can be drawn from the data. Firstly, from the SEM data the addition of kenaf fibre matrix in concrete bricks increased the pore formation in the brick microstructures that in turn seemed to affect its water absorption capacity and 
mechanical strength. The water absorption capacity of eco-bricks is increased with the increased of kenaf fibre. The flexural strength of the eco-bricks is negatively correlated with the kenaf fibre amount in the matrix. The data suggests that according to the ASTM C73 standard guideline, the eco-bricks produced from $0.5-1.5 \%$ are mostly suitable to be utilized in moderate weather conditions. Although further technical improvement is still needed for the prototypes to pass all the ASTM C73 specifications, the results shed potential R\&D of ecobricks from kenaf fibres as a significant strategy to reduce global green house gases emission in housing and manufacturing sector.

\section{ACKNOWLEDGMENT}

The authors would like to thank the National Kenaf and Tobacco Board for supplying the kenaf biomass and the staffs at Physics Department, Faculty of Science and Mathematics, Universiti Pendidikan Sultan Idris for their technical assistance.

\section{REFERENCES}

[1] G. F. Harris, The Science of Brick Making. London, UK: Biblio Life, 2009.

[2] S. S. S. Gardezi, N. Shafiq, N. A. W. A. Zawawi and S. A. Farhan, "Embodied carbon potential of conventional construction materials used in typical Malaysian single storey low cost house using Building Information Modeling (BIM)," Advanced Materials Research, vol. 1043, pp. 242- 246, 2014. DOI: 10.4028/www.scientific.net/AMR.1043.242

[3] A. Abdullah, "Bata tanpa bakar", BSc thesis, Universiti Teknologi Malaysia, 2006.

[4] A. H. Basta, M. Z .Safain and I. El-Rewainy, " Role of some treatments on enhancing the eco-friendly utilization of lignocellulosic wastes in production of cement-fiber bricks," Bio Resources, vol. 6, no. 2, pp. 1359-1375, 2011.

[5] K. S. Shibib, H. I. Qatta and M. S. Hamza, "Enhancement in thermal and mechanical properties of bricks," Thermal Science, vol.17, no.4, pp. 1119-1123, 2013. DOI: $10.2298 / T S C I 110610043 S$

[6] P. Dalmay, A. Smith, T. Chotard, P. Sahay-Turner, V. Gloaguen and P. Krausz, "Properties of cellulosic fibre reinforced plaster: influence of hemp or flax fibres on the properties of set gypsum," Journal of Materials Science, vol. 45, no. 3, pp. 793-803, 2010. DOI: 10.1007/s10853-009-4002-x

[7] N. M. Julkapli, Z. Ahmad and H. Md Akil, " Preparation and properties of kenaf dust-filled chitosan biocomposites," Composite Interfaces, vol. 15, no. 7-9, pp. 851-866, 2008.

DOI: $10.1163 / 156855408786778410$

[8] V. C. Xuan, I. Hanafi, A. R. Azura, T. Tsutomu and V. Thao, "Mechanical properties and water absorption of kenaf powder filled recycled high density polyethylene/natural rubber bio composites using mape as a compatibilizer," Bioresources, vol. 6, no. 3, pp. 3260-3271, 2011.

[9] E. Obonyo, "Developing enhanced, lignocellulosic fibre reinforcement for low-cost cementitiou construction materials," Architectural Engineering and Design

Management, vol. 8, no. 1, pp.30-41, 2012. DOI:

10.1080/17452007.2011.613216

[10] C. Chee-Ming, "Effect of natural fibres inclusion in clay bricks: Physico-mechanical properties," Geotechnical and Geological Engineering, vol. 73 no. 51, 1-8, 2011.

[11] ASTM International Standard, "Test methods for sampling and testing concrete masonry unit and relate dunit," [Online]. Available: http://goo.gl/LjBdbP [Accessed: 26 July, 2016].

[12] R. Shamsudin, H. Abdullah and S. C. Sinang, "Properties of Oil Sorbent Material Produced From Kenaf Fiber," International Journal of Environmental Science and Development, vol. 6, no. 7, pp. 551, 2015. DOI:

10.7763/IJESD.2015.V6.655 